\title{
DIFFERENCES IN THE METHYLATION OF BRAIN HISTAMINE IN VIVO BETWEEN AUDIOGENIC SEIZURE-SENSITIVE AND -RESISTANT DEERMICE
}

Richard L. Doyle, Robert A. Schatz and Otto Z. Sellinger

Laboratory of Neurochemistry, Mental Health Research Institute University of Michigan Medical Center, Ann Arbor, MI 48109

(Received in final form April 13, 1981)

\section{Summary}

We have investigated the catabolism of $\left[{ }^{3} \mathrm{H}\right]$ histamine (HA), after intraventricular (i.vt.) administration, in brains of the audiogenic seizure susceptible (SS) and resistant (SR) deermouse Percmyscus. Brains of SS mice had lower endogenous HA levels and contained less $\left[{ }^{3} \mathrm{H}\right]-\mathrm{HA} 20,60$ and 300 sec after i.vt. $\left[{ }^{3} \mathrm{H}\right]-\mathrm{HA}_{\mathrm{A}}$ than did brains of SR deermice. Twenty sec after [ $\left.{ }^{3} \mathrm{H}\right]-\mathrm{HA}$, brain $\left[{ }^{3} \mathrm{H}\right]$ methylhistamine (MeHA) levels and the resulting MeHA conversion index were found to be increased in the SS animals while later, at 60 and $300 \mathrm{sec}$, these parameters were found to be decreased. There were no SS-SR differences in the levels of brain [ $\left.{ }^{3} \mathrm{H}\right]$ methylimidazoleacetic acid. The data indicate that SS deermice catabolize exogenous HA, at least initially, more rapidly than their SR counterparts, confirming a like result noted immediately prior to seizure activity elicited by the administration of L-methionine-dl-sulfoximine in Mus.

Recent work has shown that the administration of the convulsant agent L-methionine-d,l-sulfoximine (MSO) to mice and rats (1-4), results in a significant decrease in brain S-adenosyl-Lmethionine (AdoMet) levels (5), most likely as a result of an accelerated utilization of AdoMet in several cerebral transmethylation reactions (6). These include the methylation of tRNA $(7,8)$, histamine (HA) (9), proteins and phospholipids (10). It was of interest to determine whether the observed changes in cerebral methylation are a peculiar characteristic of the MSO-induced seizure-susceptible state or whether they characterize other states of seizure-susceptibility as well. We, therefore, determined the in vitro activities of histamine-N-methyltransferase (HMT) and catechol-O-methyltransferase (COMT) in brain extracts obtained from autosomal recessive, audiogenic seizuresusceptible (SS), mutants of the deermouse Peromyscus maniculatus bairdii. HMT and COMT activities in SS brains were lower and higher, respectively, compared to HMT and COMT activities of audiogenic seizure-resistant (SR) deermouse brains (11). Since, however, in vitro measurements of enzymatic activity are performed in optimally fortified assay systems which utilize tissue preparations disrupted by homogenization procedures as the enzyme source, it was important to obtain comparative information on the 
respective in vivo rates of cerebral methylation in the $S S$ and $S R$ animals. The present results show that the methylation of cerebral HA to 1-methylhistamine (MeHA) proceeds in vivo at significantly higher initial rates in the SS than in the SR animals.

\section{Materials and Methods}

Animals. Males of the mutant epileptic (epep) Peromyscus strain used throughout this study were obtained from stocks maintained at the Mental Health Research Institute of the University of Michigan Medical Center, Ann Arbor, Michigan. The wild-type, SR (EpEp) deermice were wild-conceived animals obtained from the Museum of Zoology, University of Michigan, Ann Arbor, MI. The animals received "Teklan 4\% mouse and rat diet" and water ad lib and were housed in stainless steel cages, 1-6/cage. The ss deermice were derived from homozygous matings (epep $x$ epep) and were tested individually for clonic or tonic seizure response at least once after weaning using the key-jingling procedure of Barto (12). The epep animals were compared to the wild-type EpEp Peromyscus which are generally SR at all ages $(12,13)$. All experiments were conducted on adult mice, $70-90$ days of age.

In vivo histamine methylation and endogenous histamine levels. Histamine dihydrochloride was from Sigma (St. Louis, MO); 1 -methylhistamine and 1-methylimidazoleacetic acid were from Calbiochem (LaJolla, CA); silica gel thin layer chromatography (TLC) ${ }_{3}$ lates were from new England Nuclear (Boston, MA) and $[2,5-3 \mathrm{H}]$ histamine dihydrochloride (specific activity $7.7 \mathrm{Ci} / \mathrm{mmol}$ ) was from Amersham-Searle (Arlington Heights, IL). For intraventricular (i.vt.) injections, the mice were lightly anesthetized with ether, a small piece of scalp remgved for ease in identification of the injection site and [ $\left.{ }^{3} \mathrm{H}\right]-\mathrm{HA}$ was injected into the lateral cerebral ventricle in $10 \mu l$ of artificial cerebrospinal fluid (Merlis solution) 20,60 or 300 seconds prior to sacrifice in liquid nitrogen. The injection site was approximately $2 \mathrm{~mm}$ caudal to the Bregma and $1 \mathrm{~mm}$ lateral to the midline at a depth of $3 \mathrm{~mm}$ from the skull. To determine the accuracy of the i.vt. injection, mice were injected with methylene blue instead of $[3 \mathrm{H}]-\mathrm{HA}$. In 90 percent of the mice examined, the dye was localized in the ventricle (9). After overnight storage at $-20^{\circ} \mathrm{C}$, whole brains were rapidly removed and immediately reimmersed in liquid nitrogen, to be stored at $-80^{\circ} \mathrm{C}$. [ $\left.{ }^{3} \mathrm{H}\right]-\mathrm{HA},\left[{ }^{3} \mathrm{H}\right]$ 1 -methylhistamine (MeHA) and $\left[{ }^{3} \mathrm{H}\right] 1$-methylimidazoleacetic acid (MeIAA) were determined by an ion exchange/TLC procedure $(9,14)$. In another set of experiments (Table 1) steady state HA levels were measured in brains of mice that were not injected i.vt. with $\left[{ }^{H}\right]-H A$, using the single isotope procedure of Kobayashi and Maudsley (15), as modified by Schatz et al. (9).

\section{Results and Discussion}

Cerebral HA levels were significantly lower in SS, compared to $\mathrm{SR}$ animals (Table 1). This finding, coupled with the observation that the administration of MSO elevates brain histamine levels (9), demonstrates that elevated HA levels per se are not a reliable indicator of a seizure-susceptible state. 
TABLE 1

Brain Levels of Histamine in Audiogenic SeizureSusceptible (SS) and -Resistant (SR) Peromyscus

\begin{tabular}{lc} 
Animal & $\begin{array}{c}\text { Histamine } \\
\text { (ng/g) }\end{array}$ \\
\hline $\begin{array}{l}\text { Seizure resistant } \\
\text { Seizure susceptible } \\
\text { (SS) }\end{array}$ & $46.4 \pm 4.1 \quad(7)$ \\
\hline
\end{tabular}

Results are expressed as mean + S.E.M. Number in parentheses represents the number of animals in each experimental group.

a. $p<0.05$, compared to SR animals using the Student's t test.

To determine the in vivo rate of HA methylation in the brains of the SS and SR animals, [ $\left.{ }^{3}\right]-H A$ was injected intraventricularly and the $\left[{ }^{3} \mathrm{H}\right]-$ MeHA formed was determined 20,60 and 300 seconds later. In these experiments we also measured the radioactivity remaining (dpm/g) as $\left[{ }^{3}\right]-H A$, which permitted the calculation of the distribution of the radioactivity (percent) between $\left[{ }^{3} \mathrm{H}\right]-\mathrm{HA}$ and $\left[{ }^{3} \mathrm{H}\right]-\mathrm{MeHA}$ and the estimation of the $\mathrm{HA}$ to ${ }_{3} \mathrm{MeHA}$ conversion index (nmgl/g). Figure $1 \mathrm{~A}$ shows lower percent $\left[{ }^{3} \mathrm{H}\right]-\mathrm{HA}$ and higher percent $\left[{ }^{3} \mathrm{H}\right]-M e H A$ values in the SS animals (compared to SR animals) at 20 sec, a finding confirmed by the histograms (Fig. 1B) relating dpm/g to the time after [ ${ }^{3} \mathrm{H}-\mathrm{HA}$ administration in seconds. We alşo found that the amount of radioactivity $(\mathrm{dpm} / \mathrm{g})$ present as $\left[{ }^{3} \mathrm{H}\right]-\mathrm{HA}$ remaingd lower in the $\mathrm{SS}$ than in the $\mathrm{SR}$ animals at $60 \mathrm{sec}$, but that the $\left[{ }^{3} \mathrm{H}\right]-$ MeHA levels (dpm/g) failed to reflect this trend. Table 2 shows higher HA to MeHA conversion index values at 20 sec in the sS animals with an inversion to lower values thereafter. Mean $\left[{ }^{3} \mathrm{H}\right]-\mathrm{HA}$ specific radioactivity values (dpm/nmol) (Table 2) for SS mice were not significantly different from the corresponding SR values at any of the time intervals tested. We take this to mean that, in both groups of animals, the injected $\left[{ }^{3} \mathrm{H}\right]-\mathrm{HA}$ mixed rapidiy and uniformly with the endogenous brain $\mathrm{HA}$ pool(s).

We cannot fully account for the failure of the conversion index to remain higher in the SS than in the SR animals past the 20 sec time point. Indeed, the subsequently lower SS conversion index values are in agreement with the previous observation of lower in vitro HMT activity in brains of SS deermice (11). Further, the conversion index change is not likely due to differential rates of conversion of $\left[{ }^{3}\right]-M e H A$ to $\left[{ }^{3} \mathrm{H}\right]-M e I A A$, since we recently showed no significant difference between the in vitro activities of the MeHA-metabolizing enzyme, monoamine oxidase (MAO), type B $(16-18)$ in SS vS SR brains (11). Similarly, there were no differences in the present study between the brain $\left[{ }^{3} \mathrm{H}\right]$-MeIAA levels in either animal group (data not shown). Despite the lack of change in the in vitro activity of MAO-B (11), 

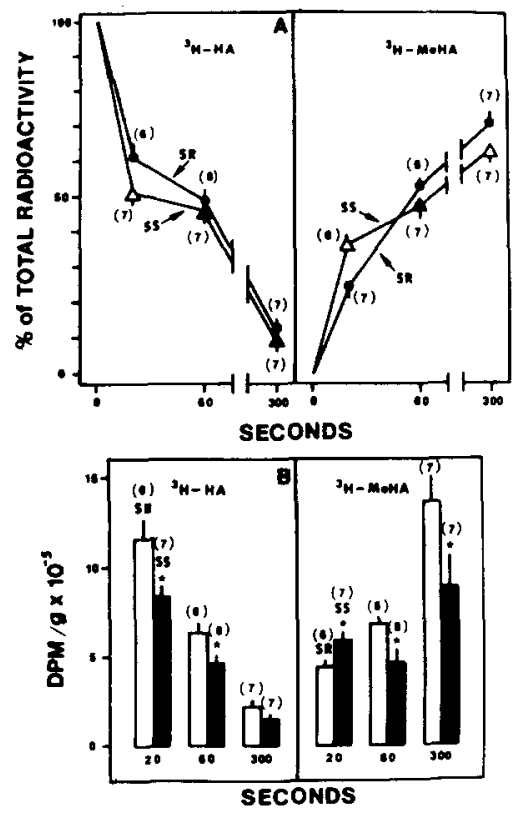

FIG. 1

\begin{abstract}
Catabolism of $\left[{ }^{3} \mathrm{H}\right]$ histamine in audiogenic seizure-susceptible (SS) and resistant (SR) peromyscus. $\left[{ }^{\mathrm{H}}\right]-\mathrm{HA}(1 \mu \mathrm{Ci} / 10 \mu \mathrm{I})$ was injected $i . v t .20,60$ and $300 \mathrm{sec}$ before sacrifice. Results in panel A are expressed as mean percent of total radioactivity \pm SEM. Open symbols denote values significantly different from $S R$ animals using the Student's t test $(p<0.05)$. Results in panel B are expressed in $\mathrm{dpm} / \mathrm{g} \times 10^{-5}$ as mean \pm S.E.M. Stars denote values significantly different from SR animals $(p<0.05)$. In both panels $A$ and $B$, the number in parentheses represents the number of animals in each experimental group.
\end{abstract}

and also because no inhibitor of MAO-B was used in this study, the possibility of appreciable differences in the in vivo rates of MeHA catabolism between SS and SB animals still remainsopen. The non-availability of sufficient [ $\left.{ }^{\mathrm{H}}\right]-\mathrm{MeHA}$ of an appropriately high specific radioactivity has, to date, precluded the testing of this pqssibility. Finally, it is conceivable that the crossover in $\left[{ }_{\mathrm{H}}\right]-$ MeHA formation from an increase at $20 \mathrm{sec}$ to a decrease at 60 and 300 sec reflects an incomplete distribution of [ $\left.{ }^{3} \mathrm{H}\right]-\mathrm{HA}$ after i.vt. administration, but previous studies utilizing this injection route have revealed no problems in this regard $(9,20)$. It should also be noted that the conversion index expression assumes identical steady state levels of brain MeHA $(19,20)$ in SS and $S R$ animals, an assumption that remains unproven in our experiments. The low SS [ $\left.{ }^{\mathrm{H}}\right]-\mathrm{MeHA}$ levels at 60 and $300 \mathrm{sec}$ 
(Fig. 1B, right panel) may therefore be interpreted to mean that the SS brains have lower amounts of MeHA, as well as HA (Table 1), compared to their SR counterparts. For this, we assume that the $\left[{ }^{3} \mathrm{H}\right]-M e H A$ formed from the injected [ $\left.{ }^{3} \mathrm{H}\right]-\mathrm{HA}$ mixed uniformly with the endogenous brain MeHA pqol ( $\mathrm{s}$ ) in both animal groups (9,20). The decreased amounts of $\left[{ }^{3} \mathrm{H}\right]-\mathrm{HA}$ (Fig. 1B, left panel) in the SS, compared to SR brains, indicate that SS deermice catabolized the

TABLE 2

Histamine Specific Radioactivity and Methylhistamine Conversion Index in Audiogenic Seizure-Susceptible (SS) and -Resistant (SR) Peromyscus.

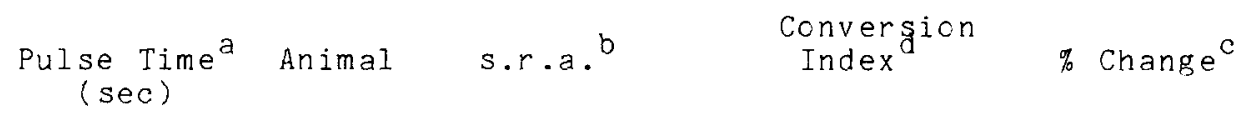

\begin{tabular}{lllll}
20 & $S R$ & $25.8 \pm 1.8(6)$ & $0.17 \pm 0.01$ & - \\
& $S S$ & $29.9 \pm 3.2(7)$ & $0.23 \pm 0.02^{e}$ & +35 \\
60 & $S R$ & $15.0 \pm 1.4(6)$ & $0.44 \pm 0.06$ & - \\
300 & $S S$ & $16.8 \pm 1.6(7)$ & $0.27 \pm 0.04$ & -39 \\
& $S R$ & $3.8 \pm 0.4(7)$ & $3.09 \pm 0.36$ & - \\
\hline
\end{tabular}

a. $\left[{ }^{3} \mathrm{H}\right]$ histamine $(1 \mu \mathrm{Ci} / 10 \mu \mathrm{l})$ was injected i. vt. 20,60 and 300 sec before sacrifice.

b. Histamine specific radioactivity expressed in dpm/nmol as mean + S.E.M. The number in parentheses represents the number of animals in each experimental group.

c. Percent change compared to SR animals.

d. Methylhistamine conversion index expressed in nmol/g as mean + S.E.M.

Conversion index: $\frac{\mathrm{dpm} / \mathrm{g}\left[{ }^{3} \mathrm{H}\right]-\text { methylhistamine }}{\text { histamine s.r.a. in dpm/nmo }}$

e. $p<0.05$ compared to SR animals (Student's $t$ test).

exogenous HA faster than the SR animals. A similar finding (i.e., a faster than control cerebral methylation of HA) was recently reported in Swiss-Webster mice following the administration of MSO (9). An alternate possibility is that $\left[{ }^{3} \mathrm{H}\right]-\mathrm{HA}$ efflux (and perhaps that of $\left[{ }^{3} \mathrm{H}\right]-M e H A$ or MeIAA) from brain is more rapid in SS than in SR mice. However, in preliminary studies, no differences in levels of radioactivity were noted in the blood of $S S$ compared to SR mice at the 300 sec time point (data not shown).

In sum, we have demonstrated that increases in the cerebral methylation of $\mathrm{HA}$ appear to correlate positively with the SS states in the peromyscus mutant and in the MSO-treated Mus (9). 


\section{Acknowledgements}

Supported by a grant from the U.S. Public Health Service, NINCDS 06294 to 0. Z. Sellinger.

\section{References}

1. L. REINER, F. MISANI and P. WEISS, Arch. Biochem. 25 447-454

2. Z. LODIN and J. KOLOUSEK, Physiol. Bohemoslov. $\underline{7}$ 87-94 (1958)

3. C. LAMAR and 0. Z. SELLINGER, Biochem. Pharmacol. 14 489-507 (1965)

4. O. Z. SELLINGER, J. M. AZCURRA and W. G. OHLSSON, J. Pharmacol. Exp. Ther. 164 212-222 (1968)

5. R. A. SCHATZ and $\overline{0 . Z}$. SELLINGER, J. Neurochem. 24 63-66 (1975)

6. R. A. SCHATZ and O.Z. SELLINGER, J. Neurochem. 25 73-78 (1975)

7. C. E. SALAS, W. G. OHLSSON and O. Z. SELLINGER, Biochem. Biophys. Res. Comm. 76 1107-1115 (1977)

8. J. DAINAT, C. E. SALAS and O. Z. SELLINGER, Biochem. Pharmacol. 27 2655-2658 (1978)

9. R. A. SCHATZ, K. FRYE and O. Z. SELLINGER, J. Pharmacol. Exp. Ther. $207794-800$ (1978)

10. R.A. SCHATZ, T. E. WILENS and O. Z. SELLINGER, Trans. Am. Neurochem. Soc. 12151 (1981)

11. R. L. DOYLE and O. Z. SELLINGER, Pharmac. Biochem. Behav. 13 589-591 (1980)

12. E. BARTO, Contr. Lab. vertebr. Biol. Univ. Mich. 74 1-15 (1956)

13. R. L. DOYLE, Ph.D. Dissertation, University of Michigan, pp. 1-69 (1978)

14. J.-C. SCHWARTZ, H. POLLARD, S. BISCHOFF, M. REHAULT and M. VERDIERE-SAHUQUE, Eur. J. Pharmacol. 16 326-335 (1971)

15. Y. KOBAYASHI and D. V. MAUDSLEY, Anal. Biochem. 46 85-90 (1972)

16. P. C. WALDMEIER, J. J. FELDTRAUER and L. MAITRE, J. Neurochem. $29785-790$ (1977)

17. O. SUZUKI, Y. KATSUMATA and M. OYA, Life Sci. 24 2227-2230 (1979)

18. L. B. HOUGH and E. F. DOMINO, J. Pharmacol. Exp. Ther. 208 422-428 (1979)

19. H. POLLARD, S. BISCHOFF and J.-C. SCHWARTZ, J. Pharmacol. Exp. Ther. $19088-99$ (1974)

20. R. A. SCHATZ, G. STRAMENTINOLI and O. Z. SELLINGER, J. Pharmacol. Exp. Ther. 216 118-124 (1981) 